As regards the other matter referred to, Mr. Tittmann does not mention the publication in which "Mr. Chaney states that the standard air to which his result is reduced weighs 0.3077 grains per cubic inch." The only publication known to me is Mr. Chaney's paper in the Proceedings of the Royal Society, and it does not contain any such statement.

I have always been taught to regard a standard weight as a standard of mass, and therefore independent of such conditions as temperature, pressure, and the material in the other scale pan; whereas, it appears that Mr. Chaney, by direction of the Board of Trade, has made a determination which is only true for a particular density of the surrounding air, and a particular density of the weights in the other pan.

For scientific purposes a standard of reference should be free from variable elements, and should be of the utmost attainable simplicity. For commercial purposes determinations to six figures are frivolous.

Mr. Tittmann's reductions appear to contain two errors. Instead of adding the weight of a cubic inch of air, he ought to have added the difference between this and the weight of the air displaced by the weights in the opposite pan. Again, he takes the metre as $39^{\circ} 3700$ inches, whereas Clarke's value is $39^{\circ} 370432$, and Kater's $39^{\circ} 37079$.

I have had some correspondence with $\mathrm{Mr}$. Chaney since the publication of my new edition, and have had an erratum slip printed, which I trust you will allow me to subjoin, as it may be useful to several of your readers

5 Princess Gardens, Belfast, 'March 28.

\section{Addenda and Corrigenda.}

Page 63. In reducing Cailletet's experiments, '0000026 should have been added instead of ooo 0039 .

Page 77. Add-Violle's determination of velocity of sound is $33 \mathrm{I} \cdot \mathrm{IO} \pm 0 \cdot \mathrm{r}$. Ann. de Chim. XIX. March, 18 go.

Page I 76, line ı. For Wuilleumeier, 1890, read Wuilleumier, I890, Lippmann method.

At end of page $164, a d d-$ Expressing $C$ in amperes, $R$ in ohms, and $T$ in seconds, the heating effect in gramme-degrees is $C^{2} R T / 4^{2} 2={ }^{2} 4 C^{2} R T$.

Page 35. Mr. Chaney's determination here quoted was not intended as a determination of the density of water, but of the apparent weight of water when weighed in air of density -OOI 21684 against brass weights of density 8.143 . The correcting factor for deducing the weight in vacuo or true density is 1 '001 0687 , which will change the value 998752 obtained in the text into ' 99982 , to compare with Tralles' 99988 .

Mr. Chaney's result is for distilled water deprived of air, and Tralles' appears to be for ordinary distilled water. According to results recently obtained by the Vienna Standards Commission (Wied. Ann., I8gr, Part 9, p. I7I), water deprived of air has the greater density, the difference being 0000032 at $0^{\circ} \mathrm{C}$., and 0000017 at $62^{\circ} \mathrm{F}$. These differences are too small to affect the above comparison.

\section{Influenza in America.}

IN my copy of " Johnson's Dictionary of the English Language in Miniature, to which are added an alphabetical account of the heathen deities and a copious chronological table of remarkable events, discoveries, and inventions, by the Rev. Joseph Hamilton, M.A., second American edition, Boston, 1806 " (12mo, pp. 276), I find on p. 275, "Influenza in North America, 1647, 1655, 1697-98, 1732, I 737, 1747, 1756-57, 176r, 1772, I781, I 789-90, i802."

It is quite possible that these dates are well known, but they are new to me, and may be of interest in connection with the recent epidemic.

Mount Hamilton, March 29.

\section{DUST COUNTING ON BEN NEVIS}

WITHIN the last few years quite a new factor has been introduced into the study of meteorologynamely, that which treats of the dust particles in the atmosphere, of the number of dust particles present in the air at any time, and the effect of dust in the air on climate and weather changes. It is now beginning to be recognized that the study of dust and its behaviour in the air forms the stepping-stone to the study of almost all meteorological problems which deal with clouds and precipitation, solar and terrestrial radiation, and in a general way with the diurnal and annual variations in the temperature and pressure of the atmosphere. Mr. Aitken's work in originating this branch of science, and in making and discussing numerous observations of the number of dust particles in the air of various places in this country, as well as on the Continent, at various altitudes, is pretty well known already (see NATURE, vol. xli. p. 394). Mr. Aitken's results and conclusions were looked upon as being of such importance as to warrant some of our leading meteorologists to apply to the Research Fund of the Royal Society for a grant to enable them to equip the Ben Nevis Observatory with Aitken's dust-counting apparatus. The application was successful, and instruments were at once ordered, and in due time erected at the Observatory.

The apparatus consists of two dust counters, one a portable form for use in the open air, and the other a laboratory form for use inside the Observatory. The latter is fixed in the middle room of the tower, and has pipes leading out to the free air, so that it is possible to observe with it in almost all sorts of weather and at any hour day or night. The principle on which these instruments are constructed, so as to make the tiny invisible particles of dust visible and easily countable, is pretty well known already. Briefly it is this. To make the particles visible, the air containing them is saturated with water vapour, and by a stroke of an air-pump it is thereafter cooled so much as to cause a condensation of the vapour on the particles, whereby these are thus made visible. Ordinary air is so dusty that if the receiver were full of such air it would be impossible to count the particles, and to make them easily countable the following process is resorted to. First, the chamber or receiver, whose capacity is accurately known, is filled with pure dustless air by means of an air-pump and filter. Then a fifth, a tenth, or any other fractional part of the amount of pure air inside is taken out, and the same amount of dusty air allowed in. In this way the density of the shower caused by condensation is completely under the observer's control. A small graduated stage is placed one centimetre from the top of the receiver, so that all the dust above this falls on to it, and by means of a magnifying glass all the particles on one or more of the small squares of the stage are easily counted. Then, by multiplying by the reciprocals of the various fractions used we arrive at the number of dust particles in a unit of the free dusty air. In making an observation, the mean of ten such tests is taken as the number of particles present for that time.

Observations were begun at the Ben Nevis Observatory with the portable instrument in February 1890 , and with the other instrument in the following summer. During the whole of that year the work done was mainly preliminary, as great difficulty was experienced in getting the dust work to fit into the general routine of Observatory work. The dust inquiry is not like some other special inquiries, that can be prosecuted for a certain time, and then discontinued after definite positive or negative conclusions thereanent have been arrived at, but must, on the other hand, be carried on side by side with the other observations of meteorological phenomena, as pressure, temperature, humidity, \&c., with any of which it is of equal importance, and having once been admitted into the general routine of meteorological observations it must be kept on. This fact was soon seen on Ben Nevis from the extraordinary variations that were observed in the dustiness of the air with changes of weather; and it was attempted to make continuous hourly observations of the dust as of the other elements. It was found, however, that this could not be done without crippling the general routine, this being as much as the two observers at the Observatory could well cope with. In February I89I

NO. I I 73, vOL. 45] 
a system of three-hourly observations of the dust particles was started, and this has been kept up with but few interruptions since. The dust observation is made immediately after the usual hourly set is completed, and it can thus be studied along with all the other hourly records in their relation to the prevailing weather.

A great many observations have in this way been accumulated during the past two years, but we have not had time for studying them in detail yet. A mere inspection, however, brings out some interesting points. One of these is the enormous variation that is observed in the number of dust particles, not only in the course of the year, but often in the course of a few hours. At sea-level the number of dust particles in the air at any time depends very much on the locality and on the wind, whether blowing from a polluted district or not. The mean of a number of observations made by Mr. Aitken at Kingairloch, in the west of Scotland, is I60o particles per cubic centimetre. In London, on the other hand, he found I00,000 per cubic centimetre, and in Paris rather more. On Ben Nevis the mean is 696 per cubic centimetre, the maximum being 14,400 per cubic centimetre, and on several occasions the minimum fell to o. A general mean does not convey a fair idea of the dustiness of the air at the mountain-top, although it may do so for places at sea-level, because there is at the former place a great daily range in the number of dust particles, depending on the rise and fall of the air past the place of observation. If there is any marked variation at sea-level it is entirely of a different character. Below are the means, as well as the maxima and mimima, of all the months that have a fairly representative number of observations.

Number of Dust Particles per cubic centimetre on Ben Nevis.

\begin{tabular}{|c|c|c|c|c|c|c|c|c|}
\hline I8go-9r. & Feb. & Mar. & April. & May. & June. & July. & Aug. & Nov. \\
\hline $\begin{array}{l}\text { Means } \\
\text { Maxima: } \\
\text { Minima }\end{array}$ & $\mid \begin{array}{r}(x, 515)^{r} \\
6,350 \\
4\end{array}$ & $\begin{array}{r}x, 037 \\
22,862 \\
0\end{array}$ & $\begin{array}{r}2,300 \\
14,400 \\
\text { II }\end{array}$ & $\begin{array}{r}x, 757 \\
4,940 \\
4\end{array}$ & $\begin{array}{r}(700) \\
3,850 \\
50\end{array}$ & $\begin{array}{r}(588) \\
4,000 \\
0\end{array}$ & $\begin{array}{r}(606) \\
x, 286 \\
67\end{array}$ & $\begin{array}{r}418 \\
3,150 \\
12\end{array}$ \\
\hline
\end{tabular}

The above table shows that the Ben Nevis air contains most dust in spring, and it is probable that sea-level air is in this respect similar; the cause of this greater amount of dust in spring than at any other time of the year being the great annual westward motion of the whole atmosphere, or at least of a considerable depth of it, at that time of the year. In a recent paper on "The Winds of Ben Nevis" (Trans. R.S.E., vol. xxxvi. p. 537), it has been shown that this is one of the very few points in which the high-and low-level winds agree, viz. in the excess of easterly winds in spring. The above means for summer are probably too low, as that summer was exceptionally cold, and the general circulation was very abnormal, and that in the direction which would tend to give low dust values. The maximum, 14,400, was observed at I p.m. on April II, I 891 ; and, as an instance of how very much the values change in a short time, at 8 a.m. that morning the number was only 350 per cubic centimetre, and by midnight it had again fallen to 600 per cubic centimetre.

The daily variation is fairly well indicated from the three-hourly observations. For the months of March, April, and May, I89I, the following are the means for the eight hours of observation :-

Number per cubic centimetre.

\begin{tabular}{|c|c|c|c|c|c|c|c|c|c|}
\hline Hour. & I & 4 & 7 & IO & $x_{3}$ & I6 & I9 & 22 & Day. \\
\hline $\begin{array}{l}\text { Means. } \\
\text { Difference } \\
\text { from mean- } \\
\text { Above. } \\
\text { Below. }\end{array}$ & $\ldots$ & $\begin{array}{l}\ldots \\
328\end{array}$ & $\dddot{2}_{24}$ & $\ddot{303}$ & $\begin{array}{c}95^{\circ} \\
9^{6} \\
\ldots\end{array}$ & $\begin{array}{c}143^{8} \\
\\
584 \\
\ldots\end{array}$ & $\begin{array}{l} \\
18 \mathrm{I} \\
\cdots\end{array}$ & $\begin{array}{l}\mathbf{1 7 5} \\
\ldots\end{array}$ & $\begin{array}{l} \\
\cdots \\
\cdots\end{array}$ \\
\hline
\end{tabular}

NO. I I 73 , VOL. 45 ]
Here there is a minimum indicated (526) at 4 a.m., and a maximum (1438) at 4 p.m. All the forenoon values are below the mean, and the evening values above it. It would appear that during the forenoon the summit of Ben Nevis is above the first or lowest cloud or dust stratum. About noon this stratum rises to the level of the summit, and during the afternoon hovers above it, and falls again late at night. From this it might be inferred that the summit is oftener clear of cloud in the early morning, and oftener enveloped in the afternoon. A table showing the number of times the top was clear during the last seven years shows that only about 30 per cent. is clear weather in which the summit is free from fog : but it does not show a daily variation as indicated by the dust values, what little it does show being quite the reverse-namely, a maximum of clear weather in the middle of the day and a minimum at night. This clearly indicates that when the dust layer falls below the summit at night, radiation at once forms an independent cap on the hill-top; and again in the afternoon, although the dust stratum envelopes the summit, the opposite radiation warms it up and prevents condensation, or rather evaporates the watery particles of the cloud. So that, contrary to public opinion, the best time to visit the summit for the sake of the "view" is the middle of the day, and not the early morning. During fine settled weather the rise and fall of this cloud stratum can be followed, but in average weather the effect of radiation completely masks it. The effect of solar radiation and nocturnal radiation on dust, as particles and as strata, is a problem that has to be studied and worked out. Very little is definitely known about it at present.

In the study of the nature and motions of clouds the dust observations will be of great value. When a fog envelopes the summit, the number of dust particles observed may vary greatly without any apparent change in the thickness of the fog, but as a rule dry thick fog contains a great amount of dust, while thin wet mist contains very little. It is when a thin drizzling mist envelopes the summit that the lowest values are always obtained, and then there is a distinct difference between the conditions at sea-level and those at the summit, the winds at the latter place differing in direction by $90^{\circ}$ or more from the winds below, and sometimes the upper winds are blowing straight out from the centre of a shallow low-pressure area, and the dust that rises with the slight ascending currents of the lower strata is almost entirely filtered out before reaching a height of 4400 feet. One of Mr. Aitken's conclusions may briefly be put as follows : Much wind, little dust; much dust, little wind. That dust seems to accumulate in the quietest places is fully borne out by the Ben Nevis observations. This is true not only horizontally, but also vertically, and it seems probable that this is what chiefly determines the position of cloud strata at all heights. And from this we may infer that the motion of clouds is much slower than that of the general aërial currents; and again, since clouds tend to form between currents, and may have as direction of motion the resultant of the directions of these currents, it follows that as indices to the motions of the upper air the velocity and motion of clouds are very unsatisfactory.

Observations of the apparent haziness of the atmosphere are made whenever it is possible, and the relations between the haziness of the air, the humidity, and the number of dust particles, have been found to be the same as what Mr. Aitken pointed out. Briefly, he found that with a constant humidity the haziness increased or diminished with the number of dust particles, and with a constant number of dust particles the haziness depended on the humidity (at least when the air was within ro or I 5 per cent. of saturation); for with increase of humidity the air became thicker, because apparently condensation begins on the dust particles before the air reaches its point of saturation. 
The dust observations promise to be of special value in the study of weather types. In some weather types, not only are the dust values very abnormal, but the daily variation is in some instances quite abnormal also, indicating that the cloud or dust strata are differently situated from what they are in average weather, and also that their daily rise and fall occur at different times. In March 1890 , the dust values show this very well : below are the three-hourly means for each of three different periods :-

\begin{tabular}{|c|c|c|c|c|c|c|c|c|}
\hline & & First & Perzo & (12d & $a y / s)$. & & & \\
\hline Hour & I & 4 & 7 & I0 & $x_{3}$ & I6 & 19 & 22 \\
\hline $\begin{array}{l}\text { cubic centi- } \\
\text { metre . }\end{array}$ & 78 & $6 \mathrm{I}$ & 78 & 67 & I I 3 & 408 & $25^{8}$ & 102 \\
\hline & & Secon & Per & $o d(3 a$ & (ays). & & & \\
\hline$"$ & 2867 & I 785 & 917 & 4733 & 4213 & 4295 & 3417 & 2533 \\
\hline & & Thir & Per & $d(5 a$ & $x y s)$ & & & \\
\hline ", & 65 & 25 & 37 & 19 & 20 & 28 & 93 & 76 \\
\hline
\end{tabular}

During the third period of five days the weather was very remarkable. A large depression was slowly progressing eastwards to the north of scotland, and the winds on Ben Nevis were blowing almost straight out from the centre, while the winds at sea-level were circulating in the normal direction. This is the usual type when low dust values are obtained; but it is difficult to quite account for the daily variation in the dust values being reversed, the higher values occurring at night, and the lower in the middle of the day. This and many other points have not been studied yet.

Dr. Buchan, in his recently published work on "Atmospheric Circulation," hinges his explanations of various atmospheric phenomena on the effect of solar and nocturnal radiation on the dust in the atmosphere, and accounts it one of the most important factors in the study of modern meteorology. The observations made at Ben Nevis Observatory clearly show that for observing the number of dust particles in the air, with a view to the observations being applied to the study of atmospheric phenomena, a true peak is of all places the best, because we can study not only the horizontal distribution of dust as brought by the different winds, but also, to a certain extent, the vertical distribution by the ascending and descending motions of the air past the place of observation. ANGUS RANKIN.
Prof. Judd, who has kindly sent me a copy, I extract the following :-

Pantelleria, an island ( 13.5 by 8 kilometres), situated between Sicily and 'Tunis, is entirely of volcanic origin. The volcanic activity would at present appear to be a shade less marked than in the "Phlegræan Fields," west of Naples.

In Pantelleria we have exhalations of $\mathrm{CO}_{2}$; hot springs (of which those at the lake called "Bagno del Acqua," among other things are, we are told, so rich in alkalies as to lather, and be used for washing clothes !), and fumaroles, some of which exhale steam harmless to vegetation, and with little if any specific effect on the rocks, while others give out sulphurous vapours at $88^{\circ} \mathrm{C}$. or more, decomposing the rocks about them.

There is but doubtful record of seismic disturbances in the island prior to the summer of 1890 . Then, however, earthquakes occurred, with elevation of part of the north coast, the cracking of cisterns, and an increase in the number and activity of the fumaroles, so that vineyards formed in some of the old craters were damaged. After more than a year's interval, earthquakes again commenced October I4, I 89 I (three days before the eruption). These were accompanied by drying up of certain springs, and apparently a further rise on the north coast, with surface cracks in that district.

As the shocks were most violent and vertical at the little town of Pantelleria itself (at the end of the island nearest the scene of eruption), they caused considerable consternation; and if one went by the account of the overstrung inhabitants, who felt shocks not recognized by the seismoscopes, one might exaggerate their violence. On the other hand, the walls of the houses, which outside the town have frequently no upper story, are, on the whole, substantially built, so that the insignificant damage done is perhaps hardly a gauge. Part of the north coast (Fig. I) appears to have been raised, in the two years,

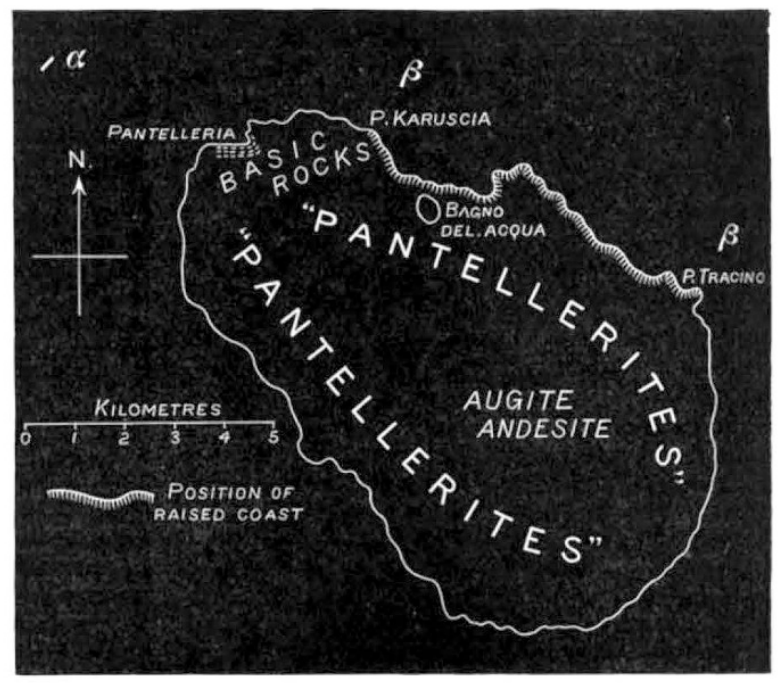

FIG. I.-Map of Pantelleria, showing the position, according to Ricco, of $(a)$ the submarine eruption of October $189 \mathrm{r}$, and $(\beta, \beta)$ of the raised coast.

some $80 \mathrm{~cm}$., the old sea-level being marked by a line of white incrustations; and we are told that, according to a recent estimate, ${ }^{2}$ the tide in this part of the Mediterranean has an amplitude of but some $8 \mathrm{~cm}$.; besides, there was the evidence of inhabitants who had bathed, boated, and fished along the coast. The submarine eruption (4 kilometres north-west of the island, Fig. I) began on

"Foerstner, "Nota preliminare sulla Geologia dell' Isola di Pantelleria" (with geological map), Boll. Com. Geol. d'Ital., x88x.

2 Prof. G. Grablovitz, "Le isorachie della marea nel Mediterraneo," Rendiconti della R. Accad. dei Lincei, I6 Agosto, I89r.

\footnotetext{
Parte 3 , vol. xi.

(a) Lyell's "Principles of Geology"; 3 (a) "South Italian Volcanoes,",pp. 64 and 65 ; and $(b)$ Giov. Platania, "I Fenomeni Sottomarini durante l'Eruzione di Vulcano (Eolie) nel r888I889," Att. Rend. Acc. Sc. Let. Art. Acireale, n. ser., vol. i., I889, pp. 16 , tables 3 .
}

NO. I 173 , VOL. 45$]$ 